\title{
Comparative Study of Autologous Ossicular Graft versus Titanium Prosthesis (TORP \& PORP) in Ossiculoplasty
}

\author{
P Thamizharasan, ${ }^{1} \mathrm{~K}^{\text {Ravi }^{1}}$
}

\begin{abstract}
Introduction
This prospective cohort study aims to analyze and compare the outcomes of ossiculoplasty in terms of hearing results, intra and post operative course, using autograft incus and titanium middle ear prosthesis.

Materials and Methods

Patients with a history of chronic ear discharge and conductive deafness were included in the study. Out of 21 patients with ossicular chain defect included in the study, 10 patients underwent ossiculoplasty with autograft incus and 11 with titanium prosthesis. Pure tone audiogram was done after three months.

$\underline{\text { Results }}$

In patients with incus ossiculoplasty, average Post operative PTA was $43.5 \mathrm{~dB} \pm 7.934 \mathrm{SD}$ and Net gain in hearing was 10.7 decibels $\pm 15.478 S D$. In patients with titanium prosthesis ossiculoplasty, average Post operative PTA was $41.4 d B \pm 4.789 S D$ and Net gain in hearing was 16 decibels $\pm 11.981 S D$.

Discussion

Three patients underwent only Tympanoplasty post operative PTA was $42 \pm 5.292 \mathrm{~dB}$ (incus- $39 \mathrm{~dB}$, titanium- $48 \mathrm{~dB}$ ) and hearing gain was $13.33 \pm 12.583$ (incus-20dB, titanium-0dB). Five patients underwent intact canal wall with Tympanoplasty: Post operative PTA was $35 \pm 3 d B$ (incus-35dB, titanium-30dB) and hearing gain was $23 \pm 15.379$ (incus-18.33dB, titanium-30dB). Thirteen patients underwent canal wall down procedure with Tympanoplasty: Post operative PTA was $45.67 \pm 5.228 \mathrm{~dB}$ (incus$50.4 d B$, titanium-41.8dB) and hearing gain was $9.33 \pm 12.309$ (incus-2.4dB, titanium-14.285dB). Complications in the short period studied were nil in both groups.

Conclusion

Incus and titanium have equal postoperative hearing but in terms of hearing gain Titanium prosthesis gave a better hearing gain than incus.
\end{abstract}

ABSTRACT

Keywords

Ossicular Prosthesis; Incus; Titanium

$\mathrm{H}$ earing is one of the most important special senses of human being. A good hearing is important for acquiring knowledge and improved productivity of human beings. A person with hearing impairment has decreased privilege of enjoying the aesthetics of life and has difficulty in carrying out his day to day activities. Reports of NSSO survey in the year 2001 suggest that there are 291 persons per one lakh population suffering from severe to profound hearing loss. ${ }^{1}$ The incidence of chronic otitis media is high in India, and ossicular chain destruction or erosion is a common complication of chronic suppurative otitis media.

Ossiculoplasty is done using either biological or alloplastic materials. ${ }^{2}$ Autograft or homograft ossicles, bone and cartilage are the biological materials used in reconstruction of ossicles. Autologous ossicles are

1 - Department of Otorhinolaryngology, Government Royapettah Hospital Kilpauk Medical College, Chennai Corresponding author:

Dr P Thamizharasan

email: thamizhent06@gmail.com 
the most preferred materials for reconstruction. The advantages with autologous ossicles are low extrusion rate, low cost, biocompatibility and no risk of disease transmission. However, the disadvantages are that they are not always available in chronically infected ears and in cases with cholesteatoma; ossicles with microsquamous deposits may lead to residual disease. The prolonged operative time to sculpt and shape, resorption or loss of rigidity of the reconstructed ossicles, possible fixation to the walls of middle ear and persistent osteitis in the ossicles are other disadvantages with autologous ossicles.

Nowadays alloplastic materials are commonly used for ossiculoplasty. They are classified as Biocompatible, Bioinert and Bioactive. Of all alloplastic materials, Titanium is an excellent biocompatible material; it is light but strong, and allows for many different prosthetic designs. ${ }^{2}$ It has good long term success rates. Titanium forms a biostable titanium oxide layer when combined with oxygen. ${ }^{2}$ Titanium has shown significant biostability in the middle ear for the past 10 years. It has low ferromagnetism. Moreover titanium is lightweight and rigid, making it a good sound conductor. The advantages are - it is available pre-sculptured with every type and design, surgery time is reduced and there is no risk of any residual or transmitted disease. However the disadvantages of titanium are cost, ossicular necrosis, extrusion, displacement and unsatisfactory hearing restoration.

There are not many studies which have proved the efficacy of these materials in terms of hearing results. In our study, we have subjected the patients with ossicular erosion to ossiculoplasty using autologous ossicular graft versus titanium prosthesis (TORP- total ossicular replacement prosthesis and PORP- partial ossicular replacement prosthesis) and compared the efficacy in terms of operative course, post operative sequelae, complications, anatomical and functional results.

\section{Materials and Methods}

The study population consisted of patients who attended the Ear, Nose and Throat (ENT) outpatient department at our hospital from December 2014 to December 2015. The study design was Prospective cohort study of patients undergoing ossiculoplasty in our hospital. Patients between 12-60 years of age suffering from chronic otitis media with ossicular erosion or ossicular discontinuity following trauma were included. Patients with eustachian tube dysfunction(viz. cleft palate patients), sensorineural and mixed hearing loss, medically unfit, having coexisting facial nerve palsy and labrynthitis, adhesive otitis media, active discharge inspite of culture specific antibiotics and disease over foot plate of stapes not amenable to complete removal were excluded.

Preoperatively patients underwent pure tone audiometry. The degree of hearing loss is assessed by taking pure tone average of hearing intensities in decibels at frequencies of 500, 1000, and 2000 Hertz. Computed tomography was done in all cases to assess the extent of middle ear pathology (cholesteatoma), ossicular chain abnormalities and inner ear anatomy.

After these investigations all patients were operated under general anesthesia after obtaining informed consent for participating in our study. During surgery the extent of disease and availability of disease free ossicles according to Austin classification ${ }^{3}$ were analysed ( $\mathrm{M}=$ Malleus, $\mathrm{S}=$ stapes, $+=$ present, - = absent).

After ensuring complete disease clearance, ossiculoplasty was done in the primary sitting itself. Autologous ossicular graft, autologous incus, if available was the first choice always. The height of incus was assessed if it was adequate from the foot plate or suprastructure to the tympanic membrane. The incus was held with ossicle holding forceps with reshaped with diamond burr creating a facet for suprastructure of stapes or flattened edge for footplate of stapes (Fig.1) and tympanic membrane or graft placed. The time taken for ossiculoplasty is noted and recorded.

If incus was not available or height of incus was inadequate, then titanium Total or Partial Ossicular Replacement Prosthesis (TORP or PORP) was used depending on the presence or absence of suprastructure of stapes. The prosthesis was measured for distance between tympanic membrane and footplate or suprastructure of stapes (Fig.2). The ossiculoplasty is done with a cartilage cap over the prosthesis as interface between prosthesis and tympanic membrane. 


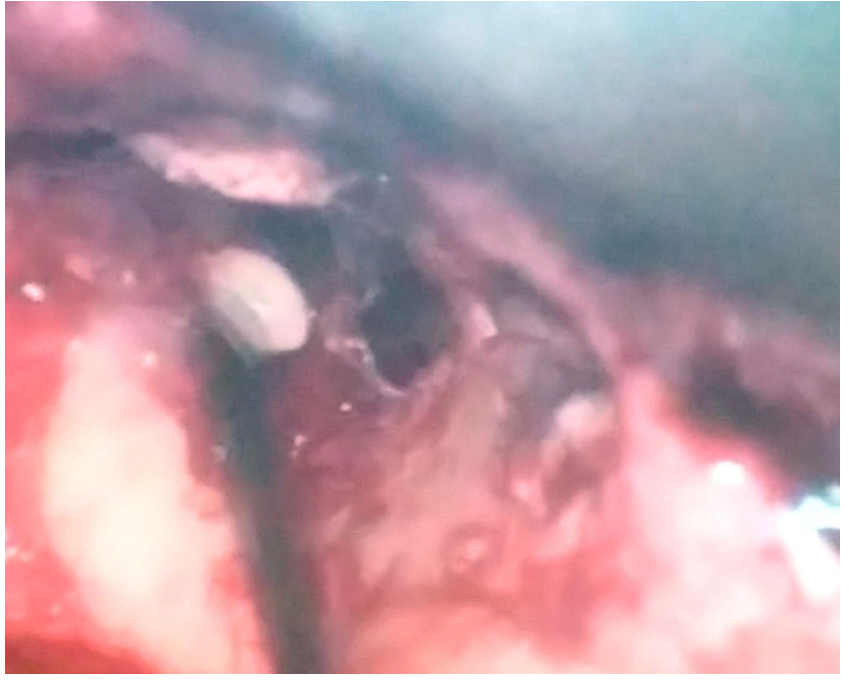

Fig.1. Incus placed over footplate of stapes

In intact canal wall mastoidectomies, tragal cartilage was harvested and in canal wall down mastoidectomies, conchal cartilage removed during meatoplasty was used. The duration taken for ossicular reconstruction was noted.

Patient was followed up with otoscopic examination every week during the first month and monthly for next 3 months. Pure tone audiometry was performed after 3 months.

\section{Results}

Among 21 patients (Table I) who underwent ossiculoplasty, 10 patients were operated with incus transposition and 11 patients with titanium. Among titanium implantees, 7 patients received TORP (Total Ossicular Replacement Prosthesis) and 4 patients received PORP (Partial Ossicular Replacement Prosthesis).

The age of patients in this study were between 14-56 years of age. There were 12 male patients and 9 female patients. 8 patients were less than 18 years of age (in whom consent was obtained from parents), 5 patients between 19-30 years, 4 patients between 31-40 years of age and 4 patients above 40 years of age.

In patients with incus ossiculoplasty, average post operative pure tone hearing level (HL) was $43.5 \mathrm{~dB}$ (SD

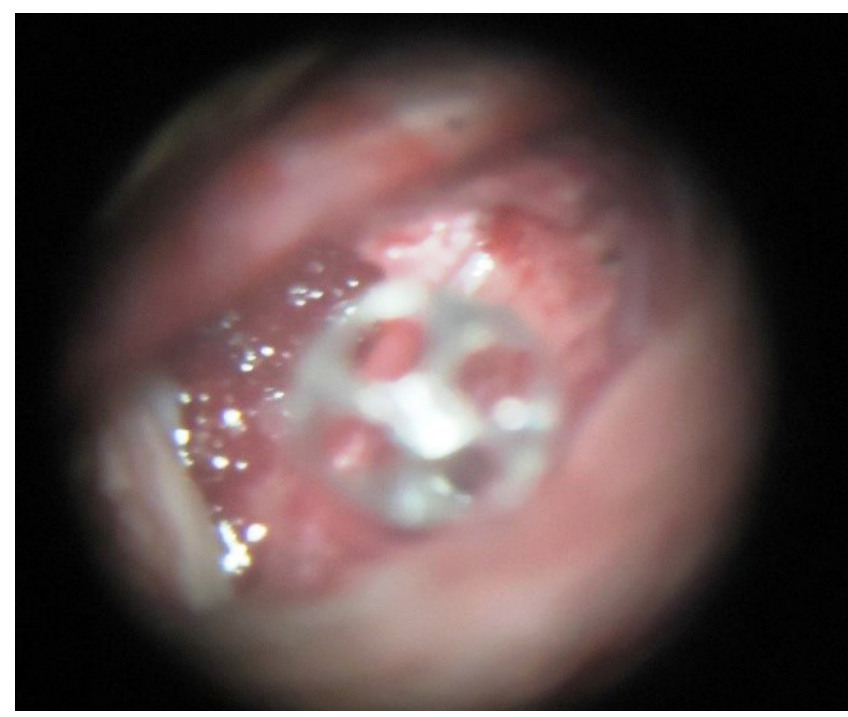

Fig.2. Titanium TORP over footplate of stapes

7.934) and net gain in hearing was 10.7 decibels (SD 15.478).

In patients with titanium prosthesis ossiculoplasty, average post operative pure tone HL was $41.4 \mathrm{~dB}$ (SD 4.789) and net gain in hearing was 16 decibels (SD 11.981). The average postoperative hearing after ossiculoplasty is $43.5 \mathrm{~dB}$.

\section{Discussion}

In patients with tympanoplasty, incus was used in 2 cases. Hearing gain was $25 \mathrm{~dB}$ for ossicular discontinuity due to trauma and hearing gain was $15 \mathrm{~dB}$ for revision case. Titanium was used in 1 case of revision tympanoplasty which had no net gain. The post op PTA including both groups was $42 \pm 5.292 \mathrm{~dB}$ (incus- $39 \mathrm{~dB}$, titanium- $48 \mathrm{~dB}$ ) $(\mathrm{p}=0.002)$ and hearing gain was $13.33 \pm 12.583$ (incus$20 \mathrm{~dB}$, titanium- $0 \mathrm{~dB})(\mathrm{p}=0.178)$.

In patients with intact canal wall mastoidectomy, Incus was used in 3 cases. All were cases of cholesteatoma. In one case suprastructure of stapes was absent and incus was placed over foot plate; the patient had a post operative hearing gain of 40 decibels. Two cases had intact suprastructure; incus repositioned over it and one had only 2 decibel hearing gain and another had 13 decibels hearing gain. Titanium was used in 2 cases. Both patients had retraction pockets without cholesteatoma. 
Titanium TORP was used in one case and had a gain of 33 decibels, Titanium PORP was used in one case and had a gain of 27 decibels. The postoperative PTA including both groups was $35 \pm 3 \mathrm{~dB}$ (incus- $35 \mathrm{~dB}$, titanium-30dB) $(\mathrm{p}=0.002)$ and hearing gain was $23 \pm$ 15.379 (incus- $18.33 \mathrm{~dB}$, titanium-30dB) $(\mathrm{p}=0.178)$.

In patients with canal wall down mastoidectomy, incus was used in 5 cases. All cases had cholesteatoma with absent suprastructure of stapes. Postoperatively one case had worsened hearing loss of $12 \mathrm{~dB}$ and another case had hearing loss of $10 \mathrm{~dB}$. Both cases probably had bridging cholesteatoma in the place of eroded ossicles and the reconstructed incus could not transmit sound as like them. The other cases had hearing gain of $17 \mathrm{~dB}$, $9 \mathrm{~dB}$ and $8 \mathrm{~dB}$. Titanium PORP was used in 3 cases ; one case had hearing loss of $3 \mathrm{~dB}$ and other two had hearing gain of $7 \mathrm{~dB}$ and $24 \mathrm{~dB}$. Titanium TORP was used in 5 cases. Suprastructure of stapes was absent in all cases. They had hearing gain of $12 \mathrm{~dB}, 16 \mathrm{~dB}$, $18 \mathrm{~dB}, 26 \mathrm{~dB}$ and one case was lost to follow up. The post op PTA including both groups was $45.67 \pm 5.228$ $\mathrm{dB}$ (incus- $50.4 \mathrm{~dB}$, titanium- $41.8 \mathrm{~dB})(\mathrm{p}=0.002)$ and hearing gain was $9.33 \pm 12.309$ (incus-2.4dB, titanium$14.285 \mathrm{~dB})(\mathrm{p}=0.178)$.

Zakzouk et al, in 2015, had 49 total ossicular reconstructions (titanium prosthesis, 40 patients; autologous incus, 9 patients) and mean air-bone gap at 2 years after surgery for the titanium prosthesis $(21 \mathrm{~dB})$ and autologous incus group $(31 \mathrm{~dB} ; \mathrm{P} \leq 0.03){ }^{4}$ Amith et al, in 2011, had done a similar study and mean preoperative

Table I : List of patients who had undergone ossiculoplasty

\begin{tabular}{|c|c|c|c|c|c|c|c|c|}
\hline $\begin{array}{l}\text { S. } \\
\text { NO. }\end{array}$ & $\begin{array}{c}\text { AGE } \\
/ \\
\text { SEX }\end{array}$ & DIAGNOSIS & $\begin{array}{c}\text { PROCEDURE } \\
\text { DONE }\end{array}$ & $\begin{array}{l}\text { OSSICULAR } \\
\text { STATUS }\end{array}$ & $\begin{array}{c}\text { INCUS / } \\
\text { TITANIUM }\end{array}$ & $\begin{array}{l}\text { PRE } \\
\text { OP } \\
\text { PTA }\end{array}$ & $\begin{array}{c}\text { POST } \\
\text { OP } \\
\text { PTA }\end{array}$ & $\begin{array}{c}\text { HEARING } \\
\text { GAIN }\end{array}$ \\
\hline \multicolumn{9}{|c|}{ Tympanoplasty alone } \\
\hline 1. & $48 / \mathrm{F}$ & $\begin{array}{l}\text { Left traumatic } \\
\text { ossicular } \\
\text { discontinuity }\end{array}$ & $\begin{array}{c}\text { Left } \\
\text { tympanoplasty }\end{array}$ & $\mathrm{M}+\mathrm{S}+$ & Incus & $65 \mathrm{~dB}$ & $40 \mathrm{~dB}$ & $+25 \mathrm{~dB}$ \\
\hline 2. & $33 / \mathrm{F}$ & $\begin{array}{c}\text { Left CSOM } \\
\text { with dry central } \\
\text { perforation }\end{array}$ & $\begin{array}{c}\text { Left } \\
\text { tympanoplasty }\end{array}$ & $\mathrm{M}+\mathrm{S}+$ & Incus & $53 \mathrm{~dB}$ & $38 \mathrm{~dB}$ & $+15 \mathrm{~dB}$ \\
\hline 3. & $43 / \mathrm{F}$ & $\begin{array}{l}\text { Right post } \\
\text { MRM residual } \\
\text { perforation }\end{array}$ & $\begin{array}{l}\text { Right revision } \\
\text { tympanoplasty }\end{array}$ & M- S- & TORP & $48 \mathrm{~dB}$ & $48 \mathrm{~dB}$ & Nil \\
\hline \multicolumn{9}{|c|}{ Intact canal wall mastoidectomy with Tympanoplasty } \\
\hline 4. & $25 / \mathrm{F}$ & $\begin{array}{l}\text { Left PSRP with } \\
\text { cholesteatoma }\end{array}$ & $\begin{array}{l}\text { Left Intact canal } \\
\text { wall }\end{array}$ & $\mathrm{M}+\mathrm{S}+$ & Incus & $40 \mathrm{~dB}$ & $38 \mathrm{~dB}$ & $+2 \mathrm{~dB}$ \\
\hline 5. & $18 / \mathrm{F}$ & $\begin{array}{c}\text { Right } \\
\text { PSRP with } \\
\text { cholesteatoma }\end{array}$ & $\begin{array}{c}\text { Right Intact canal } \\
\text { wall }\end{array}$ & $\mathrm{M}+\mathrm{S}+$ & Incus & $45 \mathrm{~dB}$ & $32 \mathrm{~dB}$ & $+13 \mathrm{~dB}$ \\
\hline 6. & $27 / \mathrm{M}$ & $\begin{array}{l}\text { Right CSOM } \\
\text { with extensive } \\
\text { granulation }\end{array}$ & $\begin{array}{l}\text { Right Intact canal } \\
\text { wall }\end{array}$ & $\mathrm{M}+\mathrm{S}-$ & Incus & $75 \mathrm{~dB}$ & $35 \mathrm{~dB}$ & $+40 \mathrm{~dB}$ \\
\hline \multicolumn{9}{|c|}{ Contd. on next page } \\
\hline
\end{tabular}




\begin{tabular}{|c|c|c|c|c|c|c|c|c|}
\hline \multicolumn{9}{|c|}{ Contd. from previous page } \\
\hline 7. & $13 / \mathrm{M}$ & $\begin{array}{l}\text { Left CSOM } \\
\text { with PSRP }\end{array}$ & $\begin{array}{l}\text { Left Intact canal } \\
\text { wall }\end{array}$ & $\mathrm{M}+\mathrm{S}-$ & PORP & $65 \mathrm{~dB}$ & $38 \mathrm{~dB}$ & $+27 \mathrm{~dB}$ \\
\hline 8. & $18 / \mathrm{F}$ & $\begin{array}{l}\text { B/L CSOM with } \\
\text { PSRP }\end{array}$ & $\begin{array}{l}\text { Right Intact canal } \\
\text { wall }\end{array}$ & $\mathrm{M}+\mathrm{S}-$ & TORP & $65 \mathrm{~dB}$ & $32 \mathrm{~dB}$ & $+33 \mathrm{~dB}$ \\
\hline \multicolumn{9}{|c|}{ Canal wall down mastoidectomy with Tympanoplasty } \\
\hline 9. & $18 / \mathrm{M}$ & $\begin{array}{c}\text { Right } \\
\text { PSRP with } \\
\text { cholesteatoma }\end{array}$ & Right CWD & $\mathrm{M}+\mathrm{S}-$ & Incus & $36 \mathrm{~dB}$ & $48 \mathrm{~dB}$ & $-12 \mathrm{~dB}$ \\
\hline 10. & $41 / \mathrm{M}$ & $\begin{array}{c}\text { Right } \\
\text { PSRP with } \\
\text { cholesteatoma }\end{array}$ & Right CWD & $\mathrm{M}+\mathrm{S}-$ & Incus & $42 \mathrm{~dB}$ & $52 \mathrm{~dB}$ & $-10 \mathrm{~dB}$ \\
\hline 11. & $35 / \mathrm{M}$ & $\begin{array}{c}\text { Left attic } \\
\text { cholesteatoma }\end{array}$ & Left CWD & M- S- & Incus & $56 \mathrm{~dB}$ & $48 \mathrm{~dB}$ & $+8 \mathrm{~dB}$ \\
\hline 12. & $56 / \mathrm{F}$ & $\begin{array}{c}\text { Right } \\
\text { cholesteatoma } \\
\text { with auto cavity }\end{array}$ & Right CWD & $\mathrm{M}+\mathrm{S}-$ & Incus & $65 \mathrm{~dB}$ & $48 \mathrm{~dB}$ & $+17 \mathrm{~dB}$ \\
\hline 13. & $35 / \mathrm{M}$ & $\begin{array}{c}\text { Left attic } \\
\text { cholesteatoma }\end{array}$ & Left CWD & M- S- & Incus & $65 \mathrm{~dB}$ & $56 \mathrm{~dB}$ & $+9 \mathrm{~dB}$ \\
\hline 14. & $27 / \mathrm{M}$ & $\begin{array}{c}\text { Right attic } \\
\text { cholesteatoma }\end{array}$ & Right CWD & M- S+ & PORP & $42 \mathrm{~dB}$ & $45 \mathrm{~dB}$ & $-3 \mathrm{~dB}$ \\
\hline 15. & $17 / \mathrm{M}$ & $\begin{array}{c}\mathrm{B} / \mathrm{L} \text { attic } \\
\text { cholesteatoma }\end{array}$ & Right CWD & M- S- & TORP & $68 \mathrm{~dB}$ & $42 \mathrm{~dB}$ & $+26 \mathrm{~dB}$ \\
\hline 16. & $29 / \mathrm{M}$ & $\begin{array}{c}\text { Left attic } \\
\text { cholesteatoma }\end{array}$ & Left CWD & M- S- & PORP & $60 \mathrm{~dB}$ & $36 \mathrm{~dB}$ & $+24 \mathrm{~dB}$ \\
\hline 17. & $23 / \mathrm{M}$ & $\begin{array}{c}\text { Right attic } \\
\text { cholesteatoma }\end{array}$ & Right CWD & M- S+ & PORP & $52 \mathrm{~dB}$ & $42 \mathrm{~dB}$ & $+7 \mathrm{~dB}$ \\
\hline 18. & $15 / F$ & $\begin{array}{l}\text { Right CSOM } \\
\text { with extensive } \\
\text { granulation }\end{array}$ & Right CWD & M- S- & TORP & $56 \mathrm{~dB}$ & $44 \mathrm{~dB}$ & $+12 \mathrm{~dB}$ \\
\hline 19. & $36 / F$ & $\begin{array}{c}\mathrm{B} / \mathrm{L} \text { attic } \\
\text { cholesteatoma }\end{array}$ & Left CWD & M- S- & TORP & $58 \mathrm{~dB}$ & $42 \mathrm{~dB}$ & $+16 \mathrm{~dB}$ \\
\hline 20. & $14 / \mathrm{M}$ & $\begin{array}{c}\text { Right } \\
\text { cholesteatoma } \\
\text { with auto cavity }\end{array}$ & Right CWD & M- S- & TORP & $63 \mathrm{~dB}$ & $45 \mathrm{~dB}$ & $+18 \mathrm{~dB}$ \\
\hline 21. & $15 / \mathrm{M}$ & $\begin{array}{c}\text { Right attic } \\
\text { cholesteatoma }\end{array}$ & Right CWD & M- S- & TORP & $72 \mathrm{~dB}$ & $\begin{array}{l}\text { Lost } \\
\text { followup }\end{array}$ & \\
\hline \multicolumn{9}{|c|}{$\begin{array}{c}\text { + - PRESENT - - ABSENT } \\
\text { CSOM - chronic suppurative otitis media, } \\
\text { PSRP- posterosuperior retraction pocket } \\
\text { CWD - canal wall down }\end{array}$} \\
\hline
\end{tabular}


AB gap values in autoincus, titanium TORP and PORP groups were 43.3 dB (SD 8.34), 44.2 dB (SD 10.17) and $42 \mathrm{~dB}$ (SD 5.7), respectively, whereas the postoperative AB gap closure values were 24.5 (SD 9.15), 30.7 (SD 15.66) and $25 \mathrm{~dB}$ (SD 6.12), respectively. ${ }^{5}$ There was a statistically significant improvement in pre operative
PTAAB gap of $43.3 \mathrm{~dB} \pm 8.34 \mathrm{SD}$ to mean postoperative $\mathrm{AB}$ gap of $24.5 \mathrm{~dB} \pm 9.16 \mathrm{SD}(\mathrm{P}=0.046)$ in autologous incus group. Woods et al, in 2008, compared incus reconstruction with the titanium prosthesis groups and found both groups yielded similar outcomes. ${ }^{6}$ Maunsell et al, in 2005, did a retrospective study of 98 patient

Table II : Statistical Analysis

\begin{tabular}{|c|c|c|c|c|c|}
\hline VARIABLES & GROUP & $\mathbf{N}$ & MEAN & STD. DEV & P-VALUE \\
\hline \multirow{2}{*}{ Age } & Incus & 10 & 33.60 & 12.349 & \multirow{2}{*}{0.038} \\
\hline & TORP/PORP & 11 & 22.73 & 9.951 & \\
\hline \multirow{2}{*}{ Pre op PTA } & Incus & 10 & 54.20 & 13.139 & \multirow{2}{*}{0.337} \\
\hline & TORP/PORP & 11 & 59.00 & 8.989 & \\
\hline \multirow{2}{*}{ Post op PTA } & Incus & 10 & 43.50 & 7.934 & \multirow{2}{*}{0.483} \\
\hline & TORP/PORP & 10 & 41.40 & 4.789 & \\
\hline \multirow{2}{*}{ Hearing gain } & Incus & 10 & 10.70 & 15.478 & \multirow{2}{*}{0.403} \\
\hline & TORP/PORP & 10 & 16.00 & 11.981 & \\
\hline \multirow{2}{*}{ Percentage change } & Incus & 10 & 15.11 & 26.79 & \multirow{2}{*}{0.303} \\
\hline & TORP/PORP & 10 & 26.02 & 18.41 & \\
\hline
\end{tabular}

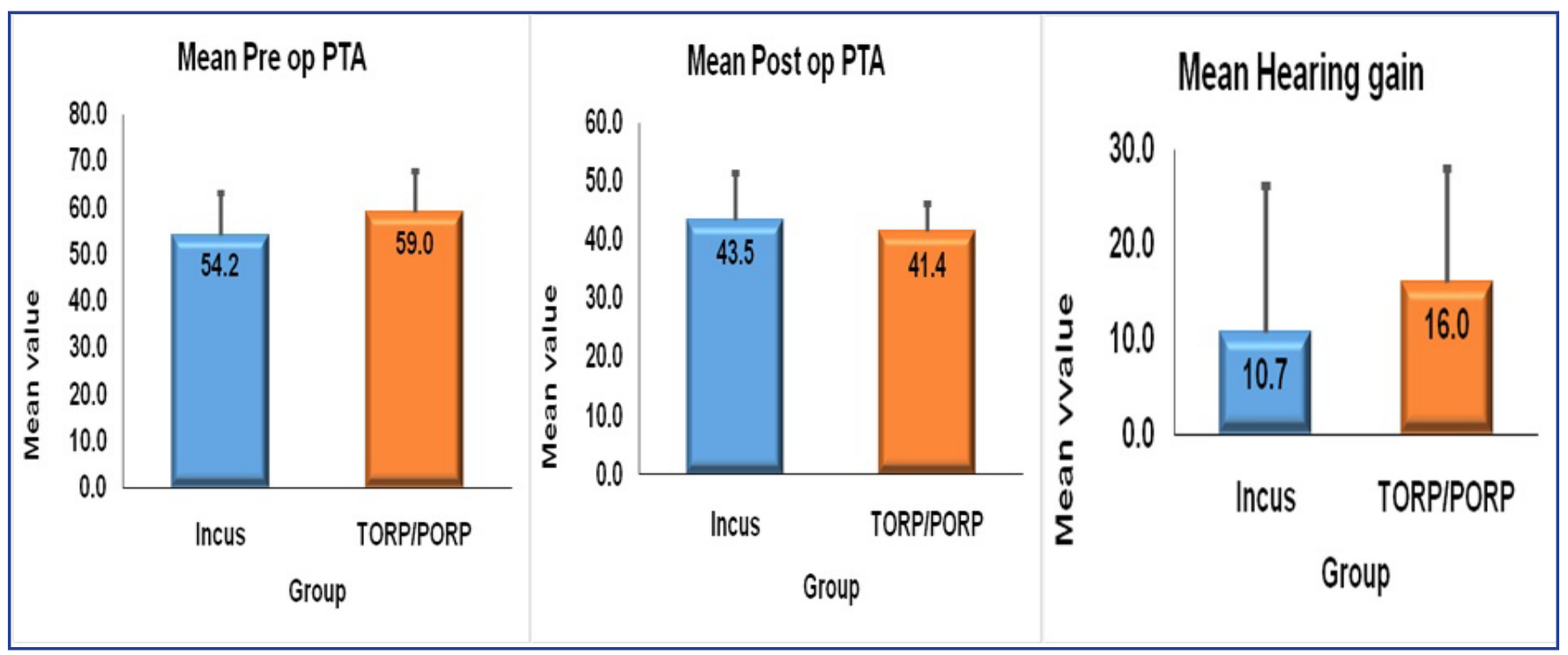

Fig.3. Overall average results between the two groups 
having type 2 with the incus and 50 patients received PORP titanium. Postoperative air bone gap was $16.9 \mathrm{~dB}$ in the titanium group and $25.5 \mathrm{~dB}$ in incus group. Gain was $18.7 \mathrm{~dB}$ in incus and $4.3 \mathrm{~dB}$ in titanium. ${ }^{7}$

In our series the post operative pure tone average at 3 months is $43.5 \mathrm{~dB} \pm \mathrm{SD} 7.934$ for incus and $41.4 \mathrm{~dB} \pm$ SD 4.789 for titanium $(p=0.483)$. In terms of hearing gain, incus-10.7, titanium-16 (p 0.403).

Zakzouk et al concluded that Titanium prosthesis ossiculoplasty gave better results than autologous incus in the absence of the stapes suprastructure and presence of a mobile footplate. ${ }^{4}$

Postoperative complications in Amith et $\mathrm{al}^{5}$ with autologous incus group were $25 \%$ as compared with titanium prosthesis in which the complication rate was $41.6 \%$ and in Maunsell et $\mathrm{al}^{7}$ rate of extrusion was $1 \%$ for incus and $4 \%$ for PORP. Other complications such as facial palsy, graft extrusion with residual perforation, severe sensory neural hearing loss, perilymph fistula and atelectasis noted in other studies were nil in our series. In the three month period there were no signs of extrusion in any of the cases. May be a longer follow up period or a challenge of ear discharge without the prescribed ear drops coverage might be needed to declare that there is no extrusion in all the cases. There was no giddiness or tinnitus in any patient. This may be due to the proper case selection with appropriate indications.

Time taken for ossiculoplasty for both incus and titanium prosthesis were almost same and had variations according to individual cases. Incus had to be reshaped, made disease free, and of adequate length to fit in. Similarly titanium prosthesis which we used in all cases has also to be altered in length and cartilage has to be harvested separately if not while meatoplasty and the time taken is considerable. In the postoperative period minor complaints such as cavity problems, otomycosis, within the three month period were equal in both cases and was independent of type of ossicular reconstruction done.

\section{Conclusion}

Ossiculoplasty definitely gives better hearing in comparison to cases where ossiculoplasty is not done. Ossiculoplasty should be done in all cases with conductive hearing loss secondary to Ossicular pathology either at primary sitting or second sitting. Incus and titanium has equal postoperative hearing (incus- $43.5 \mathrm{~dB} \pm 7.934$, titanium- $41.4 \mathrm{~dB} \pm 4.789$ ) ( $\mathrm{p}$ 0.483 ). In terms of hearing gain Titanium prosthesis gave a better hearing gain than Ossicular transposition (incus-10.7, titanium-16) (p 0.403). Autologous ossicles are not available in the desired length in all cases. Cost of titanium is a concern. Long term results are awaited. Our case series is not big enough and the period of study is one year and data after three month period follow up is not included in the study which may be suggested as pitfalls in our study.

\section{References}

1. Operational Guidelines for 12th Five Year Plan, Ministry of Halth \& Family Welfare Government of India National Programme for Prevention and Control of Deafness (NPPCD)

2. Fong JC, Michael P, Raut V. Titanium vs autograft ossiculoplasty. Acta Otolaryngol. $2010 ; 130(5): 554-8$

3. Austin DF. Ossicular reconstruction. Otolaryngology Clinics of North America. 1972; 5:689-714

4. Zakzouk A, Bonmardion N, Bouchetemble P, Lerosey Y, Marie JP. Titanium prosthesis or autologous incus for total ossicular reconstruction in the absence of the stapes suprastructure and presence of mobile footplate. Eur Arch Otorhinolaryngol. $2015 ; 272(10): 2653-7$

5. Naragund AI, Mudhol RS, Harugop AS, Patil PH. Ossiculoplasty with autologous incus versus titanium prosthesis: A comparison of anatomical and functional results Indian J Otology; 17(2):75-

6. Woods O, Fata FE, Saliba I. Ossicular reconstruction: incus versus universal titanium prosthesis. Auris Nasus Larynx. 2009; 36(4):387-92. doi: 10.1016/j.anl.2008.10.001

7. Ceccato SB, Maunsell R, MorattaGC, PortmannD Comparative results of type 2 ossiculoplasty: incus transposition versus titanium PORP. Rev Laryngol Otol Rhinol. $2005 ; 126(3): 175-9$. 